\title{
Taurine in morning spot urine for the useful assessment of dietary seafood intake in Japanese children and adolescents
}

\author{
Mari Mori", Hideki Mori, Atsumi Hamada, Yukio Yamori \\ From $17^{\text {th }}$ International Meeting of Taurine \\ Fort Lauderdale, FL, USA. 14-19 December 2009
}

\begin{abstract}
Background: Since our previous report on WHO CARDIAC Study data demonstrated that 24-hour urinary (24U) taurine (Tau) excretion was a useful biomarker of seafood (SF) intake and inversely related to the mortality rates of stroke and coronary heart diseases in the world, we determined that SF is important in the risk reduction of lifestyle related-diseases. The amounts of dietary SF intake are so far estimated from a nutritional survey or $24 U$ Tau excretion.

The sodium/potassium ratio of spot urine $(\mathrm{SU})$ and the $24 \mathrm{U}$ ratio were reported to be significantly correlated with. Therefore, we presently examined the relationship of Tau excretion in the morning SU with $24 \mathrm{U}$ Tau for simplifying the population comparison and the follow-up of SF intake changes in the process of food education program (FEP).
\end{abstract}

Methods: After informed consent was obtained, 54 children aged 6-11 years (Children) and 193 adolescents aged 13-18 years (Adolescents) participated in collecting precisely $24 \mathrm{U}$ and SU of the first urination on the same day and answered the questionnaire including age and height and weight measurements. The urine samples were measured for creatinine (Cre) and Tau, and the association of these between $24 \mathrm{U}$ and SU were analyzed.

Results: The success rates of $24 \mathrm{U}$ sampling were very high in Children and Adolescents, $96.4 \%$ and $82.4 \%$, respectively. From the result of the multiple regression analysis of SU Tau/Cre and weight we obtained formulas for predicting 24U Tau excretion in Children and Adolescents as follows: Children: $24 \mathrm{U}$ Tau $=16.3$ (weight) +314.3 (SU Tau/Cre) -175.2; and Adolescents: 24U Tau = 20.2 (weight) + 644.7 (SU Tau/Cre) - 569.4.

Conclusions: The present study established the regression equation to estimate $24 \mathrm{U}$ Tau excretion from SU Tau/ Cre and weight. These formulas are expected to contribute to the estimation of fish and SF intake and the followup of the change of the dietary behavior by FEP in Children and Adolescents.

\section{Background}

The average life expectancy of Japanese, presently the top of the average of the males and females in the world markedly increased after World War II by the improvements in sanitation as well as in diets. Japanese school lunch system started initially to solve the problem of malnutrition by supplying flour and skimmed milk

\footnotetext{
* Correspondence: mmori@mukogawa-u.ac.jp

Institute for World Health Development, Mukogawa Women's University, Nishinomiya, 6638143, Japan

Full list of author information is available at the end of the article
}

resulted later in the increased rate of the intake of meat, eggs, milk and dairy products, and Western style meals became commonly eaten by school children. This accelerated the loss of traditional Japanese dietary custom to eat rice, fish, soybean, vegetable and sea weeds $[1,2]$. The rapid Westernization of dietary custom increased health problem related to metabolic syndrome [3], such as obesity, hypertension, dyslipidemia and hyperglycaemia, not only in adults but also in children [4-7].

The Basic Law on Dietary Education, ("Shoku-Iku") was enacted in 2005 , to promote the well-balanced

\section{Biomed Central}

(c) 2010 Mori et al; licensee BioMed Central Ltd. This is an open access article distributed under the terms of the Creative Commons Attribution License (http://creativecommons.org/licenses/by/2.0), which permits unrestricted use, distribution, and reproduction in any medium, provided the original work is properly cited. 
dietary custom by the education for children and their families. Although, many food educational programs (FEP) were introduced to schools and also to local communities [8], no good objective methods were available to check the improvement of the dietary custom in the children who participated in the programs.

In our world-wide epidemiological investigation, "WHO-coordinated CARDIAC (Cardiovascular Diseases and Alimentary Comparison) Study" $[9,10]$, we could estimate the dietary intake of salt, vegetables and fruit, soy bean and sea food (SF) products by analysis of 24hour urine $(24 \mathrm{U})$ excretions of the biomarkers of these diets such as sodium, potassium, isoflavones and taurine (Tau) [11-14].

Therefore, in the present study we tried to develop a new method for estimating food intake by checking morning spot urine (SU) samples instead of $24 \mathrm{U}$ samples to confirm the change of the dietary behavior by FEP, particularly the improvement of the intake of SF, important Japanese traditional food components by examining correlation of urinary Tau excretion, a biomarker of SF intake in $24 \mathrm{U}$ and the SU samples from the same individuals.

\section{Methods}

\section{Study subjects}

We conducted many FEP's for children or adolescents since 2002 in Japan. The subjects of the present study were participants of FEP for elementary school children (Children) aged 6-11 years in Awaji-shima in 2002, and for junior and senior high school girls (Adolescents) aged 13-18 years in 2009, at Mukogawa Women's University (MWU) Junior and Senior High School in Nishinomiya, Japan.

\section{Study design}

The protocol for collecting $24 \mathrm{U}$ and SU is illustrated in Fig.1. The special jar called "Aliquot cup" which we used for WHO CARDIAC Study was adopted to collect $24 \mathrm{U}$ by sampling one fortieth of the voided urine each time of urination $[15,16]$. After filling up the questionnaires including age and height and weight measurements, all participants were given aliquot-cups and instructed to collect precisely $24 \mathrm{U}$ by discarding the first voided urine in the morning and then collecting all urine samples up to the last urine to be sampled in the following morning at the same time when the first urine was discarded in the previous morning. The SU sample $(10 \mathrm{ml})$ was collected from the last morning urine sample after sampling one fortieth of the voided urine for $24 \mathrm{U}$ collection, and after collecting both SU and $24 \mathrm{U}$ samples, participants brought their samples to school. The study protocol was approved by the ethical committee of Mukogawa Women's University, and all participants and their parents gave informed consent for the participation before enrollment.

\section{Urine sample analysis}

After 24U volume was collected, urine samples were shared into sampling tubes for the measurement of creatinine $(\mathrm{Cre})(\mathrm{mg} / \mathrm{dl})$ concentration by standard laboratory methods at SRL Inc. (Tokyo, Japan) and Tau $(\mu \mathrm{mol} / \mathrm{l})$ were estimated by high performance liquid chromatography (HPLC) (GL Sciences, Tokyo, Japan). In order to estimate the whole $24 \mathrm{~h}$ urinary Tau $(\mu \mathrm{mol} /$ day) excretion, we multiplied Tau concentration by the urinary volume of 24 hour. To estimate of $24 \mathrm{U}$ Tau from Tau/Cre ratio calculated from SU, we measured Cre and Tau concentrations in SU, and developed a

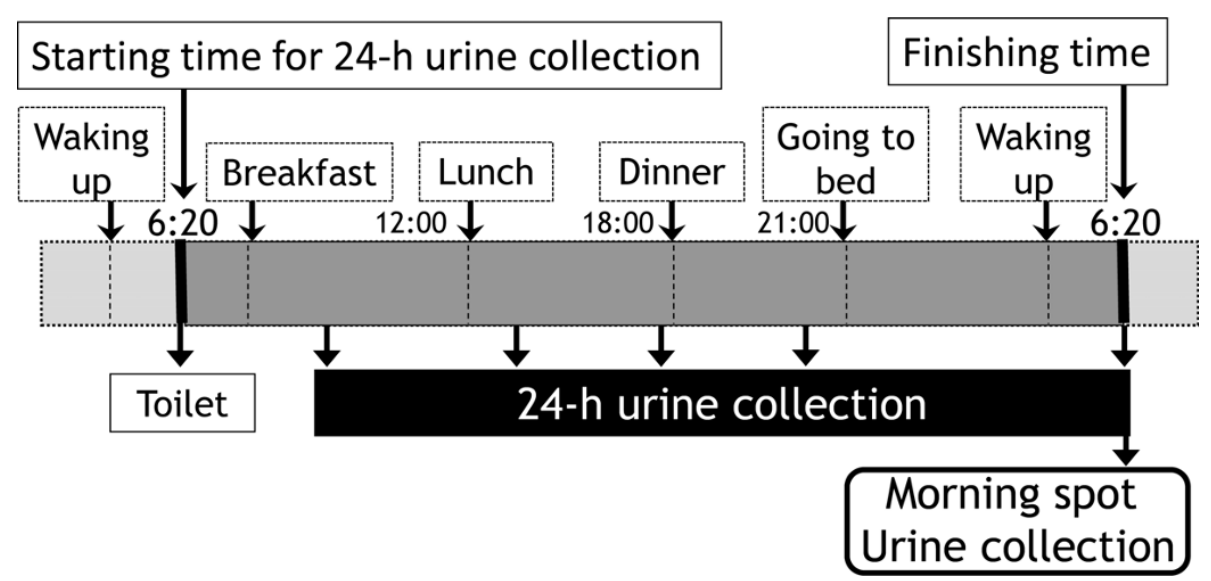

Figure 1 Urine sampling method of 24-hour and morning spot urine To void the first morning urine at toilet, for example at 6:20am, which is the starting time to collect $24 \mathrm{U}$, then collecting all urine samples up until 6:20am in the next morning. SU sampling should be sampled at the last urine collection after the procedure for sampling $24 \mathrm{U}$. 
formula to estimate $24 \mathrm{U}$ Tau excretion from checking Tau/Cre ratio in SU in Japanese Children and Adolescents.

\section{Statistical analysis}

Statistical analysis used Stat view ver. 5.0 for Macintosh. The SU Tau/Cre ratio was determined from their respective Tau and Cre concentrations of SU. Liner forward stepwise regression analysis was employed to calculate regression equation to predict $24 \mathrm{U}$ Tau. The correlation between predicted $24 \mathrm{U}$ Tau excretion from SU Tau excretions and actual 24U Tau excretion was then assessed. The comparison between estimated and measured values by $24 \mathrm{U}$ collection and sex difference in children data were carried out by student's t-test. Data were expressed as the mean $\pm \mathrm{SD}$, if not specified. Values of $\mathrm{p}<0.05$ were considered statistically significant.

\section{Results}

\section{Characteristics of the participants in this study}

Characteristics of the participants are summarized in Table 1. From among 432 participants of our FEP, 56 Children ( 25 boys and 27 girls and 364 Adolescents (all females) tried to collect $24 \mathrm{U}$, and Children and Adolescents 54 and 300 , respectively could collect $24 \mathrm{U}$ successfully. These were very high success rates of $24 \mathrm{U}$ sampling in Children and Adolescents, 96.4\% and 82.4\% respectively. Further analysis was done in 54 Children and 193 Adolescents, who could collect both $24 \mathrm{U}$ and SU successfully on the same day before their participation in our FEP.

There were no significant differences between boys and girl in Children, and significant differences were noted between Children and Adolescents in age, weight, height, 24U Tau and 24U Cre (Table 1). Because of these differences, we developed different formulas for
Children and Adolescents to estimate $24 \mathrm{U}$ Tau excretion from SU samples.

\section{Relationship in 24U Tau and SU Tau excretion}

As shown in Table 2, among correlation coefficients of $24 \mathrm{U}$ Tau excretion with personal characteristics and SU variables, the highest positive correlation scores with $24 \mathrm{U}$ Tau excretion were variables of SU Tau/Cre in Children $\left(R^{2}=0.86\right)$ and in Adolescents $\left(\mathrm{R}^{2}=0.69\right)$.

Table 3 shows the result of the multiple liner forward stepwise regression analysis. "SU Tau/Cre and weight $\left(R^{2}=0.76\right)$ " in Children was lower determination coefficient than "SU Tau/Cre and age $\left(\mathrm{R}^{2}=0.79\right)$ " and "SU Tau/Cre and height $\left(R^{2}=0.78\right)$ " of $24 U$ Tau. But $R^{2}$ is equally high, so that weight was commonly selected in both Children and Adolescents. Then we established the regression equation to predict $24 \mathrm{U}$ Tau excretion from SU Tau/Cre and weight in Children and in Adolescents. The obtained formulas for predicting $24 \mathrm{U}$ Tau excretion in Children and Adolescents were as follows;

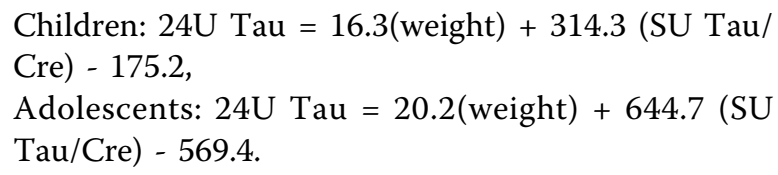

\section{Discussion}

In the results of this study, we indicated the validity of a simple method to estimate the $24 \mathrm{U}$ Tau excretion by using SU Tau/Cre and weight data. There are several methods for evaluating salt intake, such as dietary recall or records from 24 to 96 hours, food frequency questionnaires or $24 \mathrm{U}$ collection. Generally, $24 \mathrm{U}$ collection is considered to be the most reliable method to evaluate salt intake $[17,18]$. However, in this method participants

Table 1 Characteristics of this study participants

\begin{tabular}{|c|c|c|c|c|}
\hline & \multicolumn{3}{|c|}{ Children } & \multirow{2}{*}{$\begin{array}{l}\text { Adolescents } \\
(n=193)\end{array}$} \\
\hline & Boys $(n=25)$ & Girls $(n=29)$ & Total $(n=54)$ & \\
\hline Age (year) & $8.2 \pm 1.4$ & $8.0 \pm 1.4$ & $8.1 \pm 1.4$ & $16.7 \pm 1.3^{* *}$ \\
\hline Weight (kg) & $31.2 \pm 7.2$ & $29.3 \pm 8.6$ & $30.2 \pm 7.9$ & $49.5 \pm 6.9^{* *}$ \\
\hline Height (cm) & $134.0 \pm 11.0$ & $131.1 \pm 11.1$ & $132.4 \pm 10.1$ & $156.2 \pm 5.5 * *$ \\
\hline $24 U$ volume (ml) & $769.3 \pm 271.1$ & $738.2 \pm 289.1$ & $752.6 \pm 278.7$ & $906.1 \pm 582.4$ \\
\hline 24U Tau ( $\mu \mathrm{mol} / d a y)$ & $733.4 \pm 790.9$ & $759.4 \pm 905.5$ & $747.3 \pm 847.1$ & $1106.4 \pm 630.6$ ** \\
\hline SU Tau ( $\mu \mathrm{mol} / \mathrm{l})$ & $835.3 \pm 433.2$ & $1370.1 \pm 2472.0$ & $1122.5 \pm 1840.0$ & $1494.6 \pm 1085.7$ \\
\hline SU Cre (mg/dl) & $97.0 \pm 33.1$ & $90.5 \pm 40.0$ & $93.5 \pm 36.8$ & $139.2 \pm 73.9^{* *}$ \\
\hline SU Tau/Cre & $0.99 \pm 0.80$ & $1.70 \pm 0.30$ & $1.12 \pm 1.23$ & $1.04 \pm 0.69$ \\
\hline
\end{tabular}

24U: $24-h$ urine, SU: morning spot urine, Tau: taurine, Cre: creatinine. ${ }^{* *}: p<0.0001$ vs. total of Children. 
Table 2 The correlation coefficients of $24 \mathrm{U}$ Tau excretion with variables of personal characteristics and SU

\begin{tabular}{lcccccc}
\hline Variable & \multicolumn{2}{c}{ Children $(\mathbf{n}=\mathbf{5 4})$} & & \multicolumn{2}{c}{ Adolescents $(\mathbf{n}=\mathbf{1 9 3})$} \\
\cline { 2 - 3 } \cline { 6 - 7 } & Coeff. & $\mathbf{p}$ value & & Coeff. & p value \\
\hline Age (years) & 0.432 & 0.0013 & & 0.103 & 0.1559 \\
Weight $(\mathrm{kg})$ & 0.243 & 0.0764 & & 0.153 & 0.0337 \\
Height $(\mathrm{cm})$ & 0.396 & 0.0028 & & 0.125 & 0.0835 \\
SU Cre $(\mathrm{mg} / \mathrm{dl})$ & -0.232 & 0.919 & & -0.010 & 0.8956 \\
SU Tau $(\mu \mathrm{mol} / \mathrm{l})$ & 0.775 & $<0.0001$ & & 0.632 & $<0.0001$ \\
SU Tau/Cre & 0.860 & $<0.0001$ & & 0.686 & $<0.0001$ \\
\hline
\end{tabular}

Coeff: correlation coefficients, 24U: 24-h urine, SU: morning spot urine, Tau: taurine, Cre: creatinine.

must carry urine jars for 24 hours. And sometimes participants cannot obtain urine samples precisely because of forgetting the urine collection. There have been reported some studies that evaluated the effectiveness of $\mathrm{SU}$ as a simple method instead of $24 \mathrm{U}$ collection [19-21].

In our previous "WHO CARDIAC Study", 24U collection by using "Aliquot cups" was proven to be the useful and practical method to evaluate the different dietary habits of 61 populations in 25 countries [11-14]. In this study we reported $24 \mathrm{U}$ Tau excretion was positively correlated with SF intake and inversely correlated with the age adjustment mortality of coronary heart disease (CHD) and stroke [22-26]. In addition, fish and n-3 polyunsaturated fatty acid intake were reported to reduce the risk of $\mathrm{CHD}$ and sudden cardiac death in Western countries [27-31].

The risk of CHD was $40 \%$ lower among Japanese persons at the highest quintile of fish intake 8 times per week $(180 \mathrm{~g} /$ day $)$ than those who ate fish once per week (23g/day) [32]. Moreover, fish intake beneficially affects the development of type 2 diabetes [33,34]. Higher total fish intake was proven to be associated with $25 \%$ reduction of diabetes [35].
On the other hand, dietary habits of Japanese children and adolescents have been Westernized dramatically in the past few decades [4], and the Westernized diet and excessive or imbalanced intake of saturated fatty acids may be important in the pathogenesis of common lifestyle-related diseases [36] and the prevalence of the risks related to metabolic syndrome increases even in preteen Japanese children [37,38].

Eating fish and SF is a recommendable dietary habit for children's health, and morning SU collection to analyze Tau is an easy method to estimate the intake of fish and SF in children. In addition, Tau itself has been reported to be needed for the development of babies, because Tau is contained a lot in mother's milk [39], and there are many reports, that Tau is effective nutrient for the prevention of CVD [25,40], and diabetes [41]. It is important to execute FEP to make children understand good eating habits of eating fish and SF regularly which are Japanese traditional food. We think that checking SU Tau of participants in our FEP is effective for the confirmation of dietary habit improvement and for the promotion of fish and SF intake.

The limitations of the present study are the limited number of participants in Children and that only girls are studied in Adolescence. In order to apply our formulas for $24 \mathrm{U}$ Tau estimation widely to Children and Adolescents, we should collect $24 \mathrm{U}$ and SU samples from more children and also from male adolescents.

\section{Conclusions}

The present study analyzed the association of SU Tau/ Cre with $24 \mathrm{U}$ Tau to propose formulas to estimate $24 \mathrm{U}$ Tau from SU in Children and Adolescents. These formulas if utilized generally are expected to contribute to the estimation of fish and SF intake and the follow-up of the change of the dietary behavior by FEP and further to the confirmation of the health effect of fish and SF intake.

Table 3 Multiple regression analysis of SU Tau/Cre and weight to predict assessment of $24 \mathrm{U}$ Tau excretion

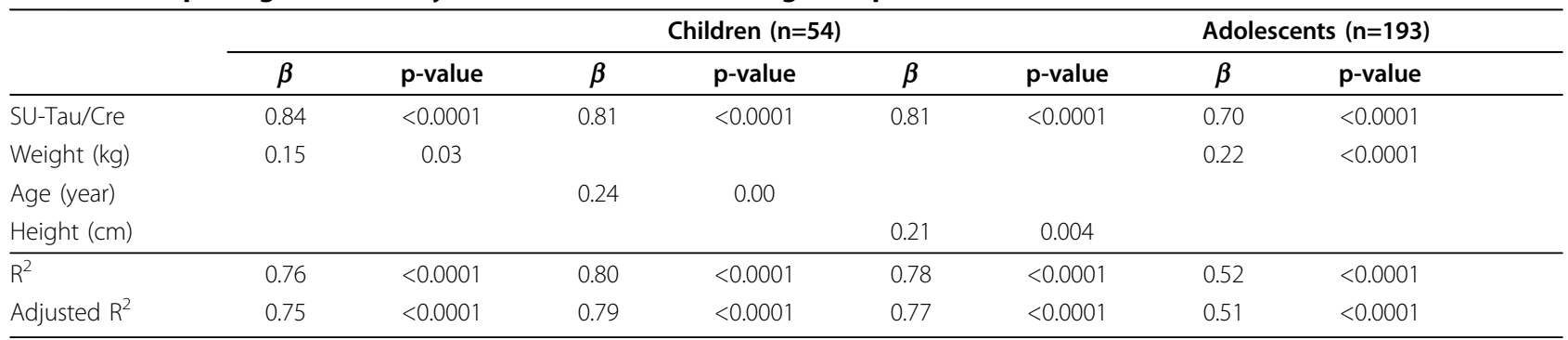

$\beta$ : regression coefficient, $95 \% \mathrm{Cl}$ : the $95 \%$ confidence interval, $24 \mathrm{U}: 24-\mathrm{h}$ urine, SU: morning spot urine, Tau: taurine, Cre: creatinine. 


\section{List of abbreviations used}

CARDIAC: Cardiovascular Diseases and Alimentary Comparison; 24U: 24 hour urine; Tau: taurine; SU: spot urine; Cre: creatinine; SF: seafood; HPLC: high performance liquid chromatography; FEP: food educational programs; Children: elementary school children; Adolescents: junior and senior high school girls; MWU: Mukogawa Women's University.

\section{Acknowledgements}

This article has been published as part of Journal of Biomedical Science Volume 17 Supplement 1, 2010: Proceedings of the 17th International Meeting of Taurine. The full contents of the supplement are available online at http://www.jbiomedsci.com/supplements/17/S1.

We thank all participants of our food educational programs for the participation and urine sample collection, and also the staff for their cooperation in the food educational programs. This work has been implemented by a study grant from Hyogo Prefecture Health Promotion Association in 2002, supported partly by Yamada Bee Farm Grant for Honeybee Research from Yamada Apiculture Center, Inc. in 2009 (to MM).

\section{Authors' contributions}

MM designed research planning and participated in the food educational programs and analyzed the data for writing the manuscript. AH performed urinary analysis by HPLC, HM coordinated research and collected urine samples, YY was a responsible doctor for supervising human study. All authors read and approved the final manuscript. MM gave final approval of the version to be published.

\section{Competing interests}

The authors declare that they have no competing interests.

Published: 24 August 2010

\section{References}

1. Nakamura T: The integration of school nutrition program into health promotion and prevention of lifestyle-related diseases in Japan. Asia Pac $J$ Clin Nutr 2008, 17 Suppl 1:349-351.

2. Melby M K, Utsugi M, Miyoshi M, Watanabe S: Overview of nutrition reference and dietary recommendations in Japan: application to nutrition policy in Asian countries. Asia Pac J Clin Nutr 2008, 17 Suppl 2:394-398

3. Ikeda J, Nagata H: Dietary and life-style characteristics and physical condition of school children. Nippon Koshu Eisei Zasshi. 1994, 41:294-310, Japanese.

4. Murata M: Secular trends in growth and changes in eating patterns of Japanese children. Am J Clin Nutr 2000, 72 (5 Suppl):1379S-1383S.

5. National High Blood Pressure Education Program Working Group on High Blood Pressure in Children and Adolescents: The fourth report on the diagnosis, evaluation, and treatment of high blood pressure in children and adolescents. Pediatrics 2004, 114:555-576.

6. Yoshinaga M, Sameshima K, Tanaka Y, Arata M, Wada A, Takahashi H: Association between the number of cardiovascular risk factors and each risk factor level in elementary school children. Circ J 2008, 72:1594-7.

7. Nakanishi T, Li R, Liu Z, Yi M, Nakagawa Y, Ohzeki T: Sexual dimorphism in relationship of serum leptin and relative weight for the standard in normal-weight, but not in overweight, children as well as adolescents. Eur J Clin Nutr 2001, 55:989-93.

8. Mori M, Xu JW, Mori H, Ling CF, Wei GH, Yamori Y: Comparative studies on 24-hour urinary excretion in Japanese and Chinese adults and children-need for nutritional education. Adv Exp Med Biol 2009, 643:399-405.

9. WHO Collaborating Center on Primary Prevention of Cardiovascular Diseases, Cardiovascular Diseases for Research Unit: WHO CARDIAC (Cardiovascular Diseases and Alimentary Comparison) Study Protocol and Manual of Operations. Geneva: WHO 1986

10. Yamori Y: Preliminary report of CARDIAC study: Cross-sectional multicenter study on dietary factors of cardiovascular diseases. CARDIAC Study Group. Clin Exp Hypertens A 1989, 11:957-72.

11. Yamori $Y$, Nara Y, Mizushima S, Mano M, Sawamura M, Kihara M, Horie R: International cooperative study on the relationship between dietary factors and blood pressure: a preliminary report from the Cardiovascular
Diseases and Alimentary Comparison (CARDIAC) Study The CARDIAC Cooperative Study Research Group. Nutr Health 1992, 8:77-90.

12. Yamori Y: Worldwide epidemic of obesity: hope for Japanese diets. Clin Exp Pharmacol Physiol 2004, 31(Suppl 2):S2-4.

13. Liu L, Ikeda K, Yamori Y, WHO-CARDIAC Study Group: Inverse relationship between urinary markers of animal protein intake and blood pressure in Chinese: results from the WHO Cardiovascular Diseases and Alimentary Comparison (CARDIAC) Study. Int J Epidemiol 2002, 31:227-33.

14. Yamori Y, Liu L, Mori M, Sagara M, Murakami S, Nara Y, Mizushima S: Taurine as the nutritional factor for the longevity of the Japanese revealed by a world-wide epidemiological survey. Adv Exp Med Biol 2009, 643:13-25.

15. Yamori $Y$, Nara $Y$, Kihara $M$, Mano $M$, Horie R: Simple method for sampling consecutive 24-hour urine for epidemiological and clinical studies. Clin Exp Hypertens A 1984, 6:1161-7.

16. Nara Y, Kihara M, Mano W, Horie R, Yamori Y: 'Aliquot cups', simple method for collecting consecutive 24-hour urine samples for epidemiological and clinical studies. Nutritional Prevention of Cardiovascular Disease Orlando: Academic Press 1984, 211-6.

17. Yamori Y, Kihara M, Fujikawa J, Soh Y, Nara Y, Ohtaka M, Horie R, Tsunematsu T, Note S, Fukase M: Dietary risk factors of stroke and hypertension in Japan - Part 1: Methodological assessment of urinalysis for dietary salt and protein intakes. Jpn Circ J 1982, 46:933-8.

18. Luft FC, Miller JZ, Lyle RM, Melby CL, Fineberg NS, McCarron DA, Weinberger MH, Morris CD: The effect of dietary interventions to reduce blood pressure in normal humans. J Am Coll Nutr 1989, 8:495-503.

19. Kawasaki T, Ueno M, Uezono K, Kawazoe N, Nakamuta S, Ueda K, Omae T: Average urinary excretion of sodium in 24 hours can be estimated from a spot-urine specimen. Jpn Circ J 1982, 46:948-53.

20. Tanaka T, Okamura T, Miura K, Kadowaki T, Ueshima H, Nakagawa $H$ Hashimoto T: A simple method to estimate populational 24-h urinary sodium and potassium excretion using a casual urine specimen. J Hum Hypertens. 2002, 16:97-103.

21. Mann S J, Gerber L M: Estimation of 24-hour sodium excretion from spot urine samples. J Clin Hypertens (Greenwich) 2010, 12:174-180.

22. Yamori Y, Nara Y, Mizushima S, Sawamura M, Horie R: Nutritional factors for stroke and major cardiovascular diseases: International epidemiological comparison of dietary prevention. Health Rep 1994, 6:22-7.

23. Yamori Y, Liu L, Mori M, Sagara M, Murakami S, Nara Y, Mizushima S: Taurine as the nutritional factor for the longevity of the Japanese revealed by a world-wide epidemiological survey. Adv Exp Med Biol 2009, 643:13-25

24. Yamori Y, Liu L, Mizushima S, Ikeda K, Nara Y, CARDIAC Study Group: Male cardiovascular mortality and dietary markers in 25 population samples of 16 countries. J Hypertens 2006, 24:1499-505.

25. Yamori Y, Murakami S, Ikeda K, Nara Y: Fish and lifestyle-related disease prevention: experimental and epidemiological evidence for antiatherogenic potential of taurine. Clin Exp Pharmacol Physiol 2004, 31(Suppl 2):S20-S23.

26. Yamori Y, Liu L, Ikeda K, Miura A, Mizushima S, Miki T, Nara Y, WHOCARDIAC Study Group: Distribution of twenty-four hour urinary taurine excretion and association with ischemic heart disease mortality in 24 populations of 16 countries: Results from the WHO-CARDIAC study. Hypertens Res. 2001, 24:453-7.

27. Albert CM, Hennekens CH, O'Donnell CJ, Ajani UA, Carey VJ, Willett WC Ruskin JN, Manson JE: Fish consumption and the risk of sudden cardiac death. JAMA 1998, 279:23-28.

28. Rissanen T, Voutilainen S, Nyyssonen K, Lakka TA, Salonen JT: Fish oilderived fatty acids, docosahexaenoic acid and docosapentaenoic acid, and the risk of acute coronary events: the Kuopio ischaemic heart disease risk factor study. Circulation 2000, 102:2677-2679.

29. Hu FB, Bronner L, Willett WC, Stampfer MJ, Rexrode KM, Albert CM, Hunter D, Manson JE: Fish and omega-3 fatty acid intake and risk of coronary heart disease in women. JAMA 2002, 287:1815-1821.

30. Albert CM, Campos H, Stampfer MJ, Ridker PM, Manson JE, Willett WC, Ma J: Blood levels of long-chain n-3 fatty acids and the risk of sudden death. N Engl J Med 2002, 346:1113-1118.

31. Lemaitre RN, King IB, Mozaffarian D, Kuller LH, Tracy RP, Siscovick DS: N-3 polyunsaturated fatty acids, fatal ischemic heart disease, and nonfatal 
myocardial infarction in older adults: the Cardiovascular Health Study. Am J Clin Nutr 2003, 77:319-325.

32. Iso H, Kobayashi M, Ishikawa J, Sasaki S, Okada K, Kita Y, Kokubo Y, Tsugane S, The JPHC Study Group: Intake of fish and n3 fatty acids and risk coronary heart diseases among Japanese: The Japan public health centre-based (JPHC) study cohort. Circulation 2006, 113:195-202.

33. Nkondjock A, Receveur O: Fish -seafood consumption, obesity, and risk of type 2diabetes: an ecological study. Diabetes Metab 2003, 29:635-42.

34. Martín de Santa Olalla L, Nutr Hosp: N-3 fatty acids in glucose metabolism and insulin sensitivity. Nutr Hosp 2009, 24:113-27.

35. Patel PS, Sharp SJ, Luben R, Khaw KT, Bingham SA, Wareham N J: Association between type of dietary fish and seafood intake and the risk of incident type 2 diabetes - The European prospective investigation of cancer (EPIC) - Norfolk cohort study. Diabetes care 2009, 32:1857-63.

36. Dolecek TA: Epidemiological evidence of relationships between dietary polyunsaturated fatty acids and mortality in the multiple risk factor intervention trial. Proc Soc Exp Biol Med 1992, 200:177-182.

37. Yoshinaga M, Tanaka S, Shimago A, Sameshima K, Nishi J, Nomura Y, Kawano Y, Hashiguchi J, Ichiki T, Shimizu S: Metabolic syndrome in overweight and obese Japanese children. 2005, 13:1135-1140.

38. Ishikawa M, Arai S, Takano M, Hamada A, Kunimasa K, Mori M: Taurine's health Influence on Japanese high school girls. J Biomed Sci 2010, in this issue.

39. Chesney RW, Helms RA, Christensen M, Budreau AM, Han X, Sturman JA: The role of taurine in infant nutrition. Adv Exp Med Biol. 1998, 442:463-76.

40. Xu YJ, Arneja AS, Tappia PS, Dhalla NS: The potential health benefits of taurine in cardiovascular disease. Exp Clin Cardiol 2008, 13:57-65.

41. Schaffer SW, Azuma J, Mozaffari M: Role of antioxidant activity of taurine in diabetes. Can J Physiol Pharmacol 2009, 87:91-9.

doi:10.1186/1423-0127-17-S1-S43

Cite this article as: Mori et al: Taurine in morning spot urine for the useful assessment of dietary seafood intake in Japanese children and adolescents. Journal of Biomedical Science 2010 17(Suppl 1):S43.

\section{Submit your next manuscript to BioMed Central and take full advantage of:}

- Convenient online submission

- Thorough peer review

- No space constraints or color figure charges

- Immediate publication on acceptance

- Inclusion in PubMed, CAS, Scopus and Google Scholar

- Research which is freely available for redistribution

Submit your manuscript at www.biomedcentral.com/submit 